\title{
System Characterization Report on the Gaofen-1
}

Chapter B of

System Characterization of Earth Observation Sensors

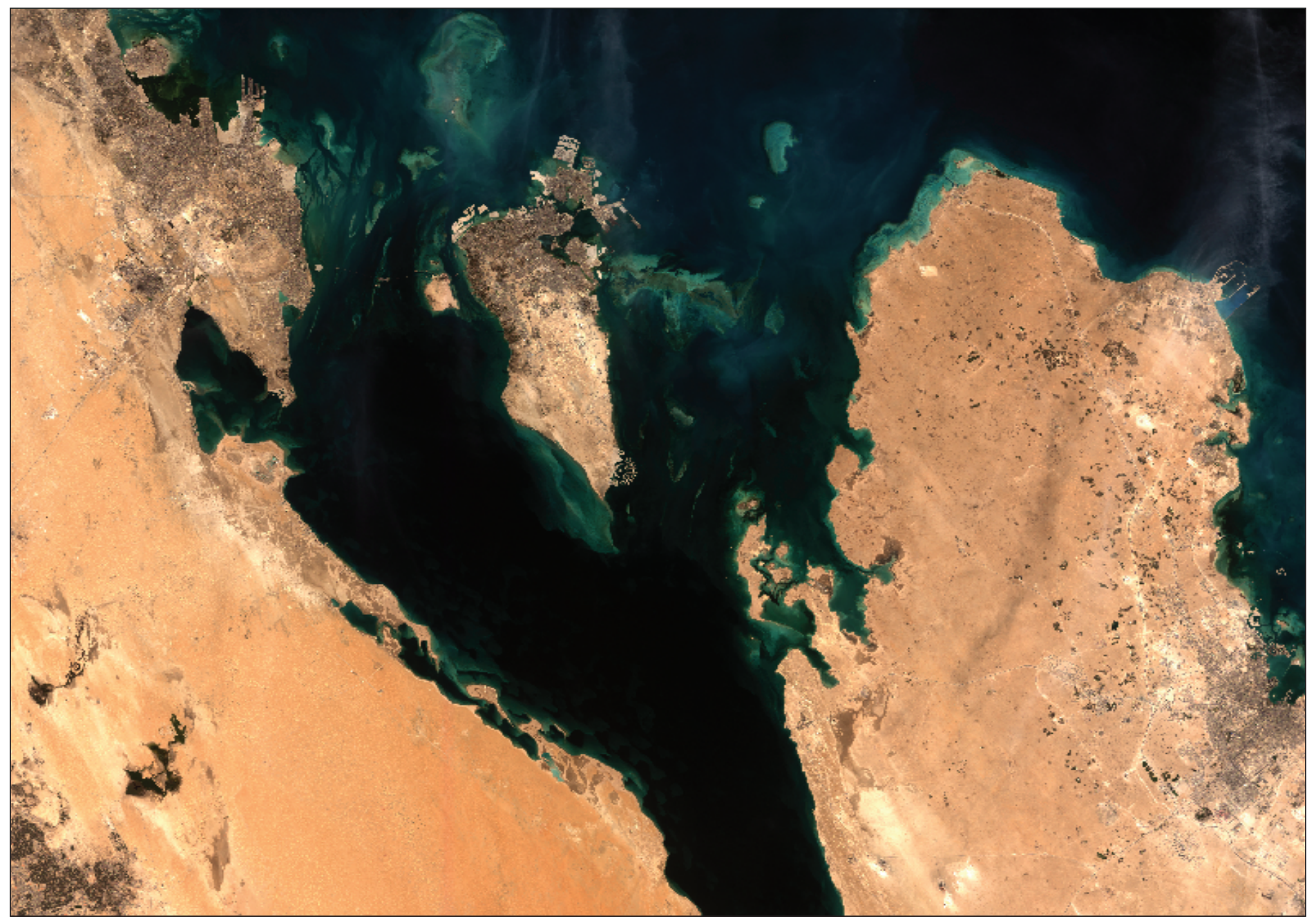

Open-File Report 2021-1030-B 
Cover: A true color image of the Kingdom of Bahrain captured by the Gaofen-1 wide field of view camera. Image courtesy of China National Space Administration Earth Observation and Data Center. 


\section{System Characterization Report on the Gaofen-1}

By Mahesh Shrestha, ${ }^{1}$ Aparajithan Sampath, ${ }^{1}$ Shankar N. Ramaseri Chandra, ${ }^{1}$

Jon B. Christopherson, Jerad Shaw, ${ }^{1}$ Gregory L. Stensaas, ${ }^{1}$ and Cody Anderson ${ }^{2}$

Chapter B of

System Characterization of Earth Observation Sensors

Compiled by Shankar N. Ramaseri Chandra ${ }^{1}$

${ }^{1}$ KBR, Inc., under contract to the U.S. Geological Survey.

${ }^{2}$ U.S. Geological Survey.

Open-File Report 2021-1030-B 


\section{U.S. Geological Survey, Reston, Virginia: 2021}

For more information on the USGS - the Federal source for science about the Earth, its natural and living resources, natural hazards, and the environment-visit https://www.usgs.gov or call 1-888-ASK-USGS.

For an overview of USGS information products, including maps, imagery, and publications, visit https://store.usgs.gov/.

Any use of trade, firm, or product names is for descriptive purposes only and does not imply endorsement by the U.S. Government.

Although this information product, for the most part, is in the public domain, it also may contain copyrighted materials as noted in the text. Permission to reproduce copyrighted items must be secured from the copyright owner.

\section{Suggested citation:}

Shrestha, M., Sampath, A., Ramaseri Chandra, S.N., Christopherson, J.B., Shaw, J., Stensaas, G.L., and Anderson, C., 2021, System characterization report on the Gaofen-1, chap. B of Ramaseri Chandra, S.N., comp., System characterization of Earth observation sensors: U.S. Geological Survey Open-File Report 2021-1030, 11 p., https://doi.org/10.3133/ofr20211030B.

ISSN 2331-1258 (online) 


\section{Contents}

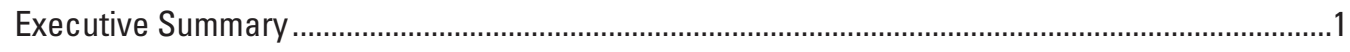

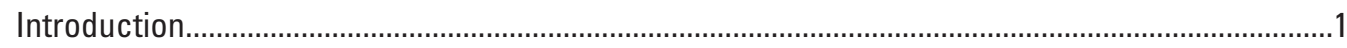

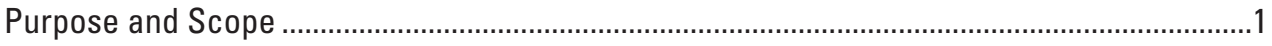

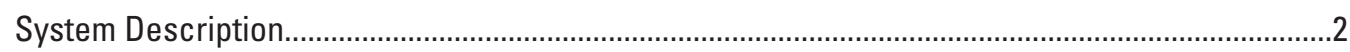

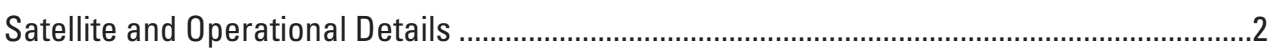

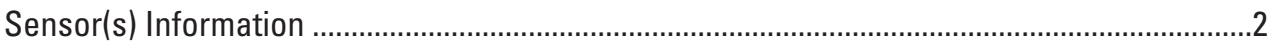

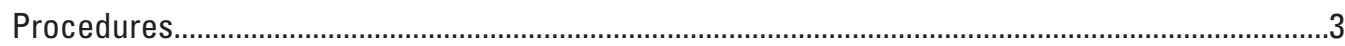

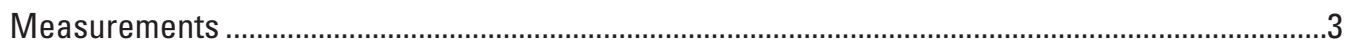

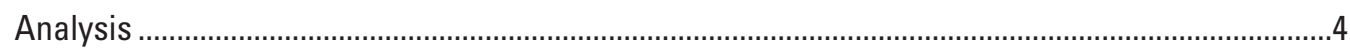

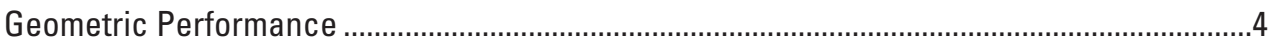

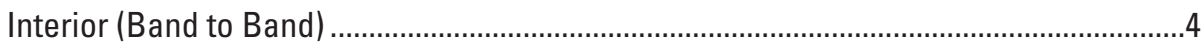

Exterior (Geometric Location Accuracy) .........................................................................

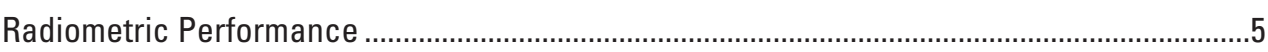

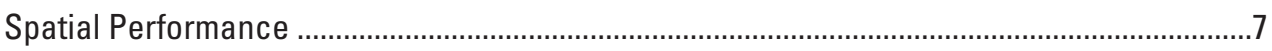

Summary and Conclusions .......................................................................................................

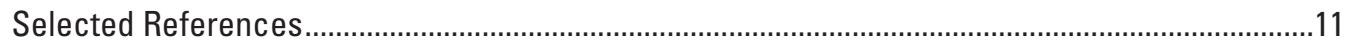

\section{Figures}

1. Graph showing Gaofen-1 relative spectral response........................................................

2. Graph showing relative geometric error comparison for Landsat 8 Operational Land Imager and Gaofen-1...................................................................................

3. Graph showing relative geometric error comparison for Landsat 8 Operational Land Imager and Gaofen-1 after bias removal ................................................................

4. Graph showing Top of Atmosphere reflectance comparison between Gaofen-1 wide field of view camera 2 and Landsat 8 Operational Land Imager over Egypt 1.........8

5. Graphs showing Top of Atmosphere reflectance difference between Gaofen-1 wide field of view camera 2 and Landsat 8 Operational Land Imager over Egypt 1.........9

6. Graph showing Top of Atmosphere reflectance comparison between Gaofen-1 wide field of view camera 3 and Landsat 8 Operational Land Imager over Libya 4 .........9

7. Graphs showing Top of Atmosphere reflectance difference between Gaofen-1 wide field of view camera 3 and Landsat 8 Operational Land Imager over Libya 4 ........10 


\section{Tables}

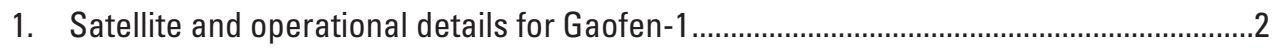

2. Imaging sensor details for Gaofen-1 .....................................................................................

3. U.S. Geological Survey measurement results ................................................................4

4. Band-to-band registration error.......................................................................................

5. Geometric error relative to Landsat 8 Operational Land Imager.........................................5

6. Top of Atmosphere reflectance comparison between Gaofen-1 wide field of view camera 2 and Landsat 8 Operational Land Imager over Egypt 1..............................

7. Top of Atmosphere reflectance comparison between Gaofen-1 wide field of view camera 3 and Landsat 8 Operational Land Imager over Libya 4

8. Spatial performance of Gaofen-1

5

\section{Conversion Factors}

International System of Units to U.S. customary units

\begin{tabular}{ccc}
\hline Multiply & By & To obtain \\
\hline & Length & foot $(\mathrm{ft})$ \\
meter $(\mathrm{m})$ & 3.281 & yard $(\mathrm{yd})$ \\
\hline
\end{tabular}

\section{Abbreviations}

$\begin{array}{ll}\text { ECCOE } & \text { Earth Resources Observation and Science CaI/Val Center of Excellence } \\ \text { GSD } & \text { ground sample distance } \\ \text { JACIE } & \text { Joint Agency Commercial Imagery Evaluation } \\ \text { OLI } & \text { Operational Land Imager } \\ \text { USGS } & \text { U.S. Geological Survey }\end{array}$




\title{
System Characterization Report on the Gaofen-1
}

\author{
By Mahesh Shrestha, ${ }^{1}$ Aparajithan Sampath, ${ }^{1}$ Shankar N. Ramaseri Chandra, ${ }^{1}$ Jon B. Christopherson, Jerad \\ Shaw, ${ }^{1}$ Gregory L. Stensaas, ${ }^{1}$ and Cody Anderson ${ }^{2}$
}

\section{Executive Summary}

This report addresses system characterization of Gaofen-1 and is part of a series of system characterization reports produced and delivered by the U.S. Geological Survey Earth Resources Observation and Science Cal/Val Center of Excellence in 2020. These reports present the detail methodology and procedures for characterization; present technical and operational information about the specific sensing system being evaluated; and provide a summary of test measurements, data retention practices, data analysis results, and conclusions.

Gaofen represents a series of Chinese high-resolution Earth observation satellites. More than 12 satellites have been launched in the Gaofen series, beginning with Gaofen-1 in 2013. Satellites within the series have varying infrared, radar, and optical imaging capabilities. The primary goal for the satellite is to provide near real-time observations for climate change monitoring, geographical mapping, precision agriculture support, environmental and resource surveying, and disaster prevention. More information on Chinese satellites and sensors is available within the "2020 Joint Agency Commercial Imagery Evaluation-Remote Sensing Satellite Compendium" and at http://www.cnsageo.com/\#/detailIndex? secondIndex $=2 \& \mathrm{id}=3 \&$ code $=8$.

The Earth Resources Observation and Science $\mathrm{Cal} / \mathrm{Val}$ Center of Excellence System Characterization team completed data analyses to characterize the geometric (interior and exterior), radiometric, and spatial performances. Results of these analyses indicate that Gaofen- 1 has an interior geometric performance of -0.48 meter $(\mathrm{m})(-0.03$ pixel) northing and $0.42 \mathrm{~m}(0.03$ pixel) easting offset for band $1,-0.99 \mathrm{~m}$ $(-0.06$ pixel) northing and $-0.38 \mathrm{~m}(-0.02$ pixel) easting offset for band $2,-0.45 \mathrm{~m}(-0.03)$ northing and $0.83 \mathrm{~m}(0.05$ pixel $)$ easting offset for band $3,-3.20 \mathrm{~m}(-0.20$ pixel $)$ northing and $1.44 \mathrm{~m}(0.09$ pixel) easting offset for band 4 in band-to-band registration. Similarly, Gaofen-1 has an exterior geometric performance of $7.50 \mathrm{~m}(0.48$ pixel $)$ easting and $109.50 \mathrm{~m}$ (7.30 pixels) northing offset in comparison to the Landsat 8 Operational Land Imager; a radiometric performance in the range of -0.014 to 0.149 (absolute reflective difference); and

\footnotetext{
${ }^{1}$ KBR, Inc., under contract to the U.S. Geological Survey.

${ }^{2}$ U.S. Geological Survey.
}

a spatial performance in the range of 1.1 to 2.0 pixels at full width at half maximum, with a modulation transfer function at a Nyquist frequency in the range of 0.040 to 0.250 .

\section{Introduction}

Gaofen-1 is a high-resolution multispectral satellite launched in 2013 by China on a Long March-2D rocket from the Jiuquan Satellite Launch Center, Ejin Banner, Alxa League, Inner Mongolia, China. Gaofen-1 is the first satellite in the China High-resolution Earth Observation System. The satellite is based on the China Academy of Space Technology-2000 bus built by the Shanghai Academy of Spaceflight Technology for the China National Space Administration. Gaofen-1 carries a panchromatic and multispectral camera-1 and a wide field of view camera for highresolution Earth monitoring. Gaofen-1 is the first satellite of Gaofen series. Satellites within the series have varying infrared, radar, and optical imaging capabilities. The primary goal for the satellite is to provide near real-time observations for climate change monitoring, geographical mapping, precision agriculture support, environmental and resource surveying, and disaster prevention.

The data analysis results provided within this report have been derived from approved Joint Agency Commercial Imagery Evaluation (JACIE) processes and procedures. JACIE was formed to leverage resources from several Federal agencies for the characterization of remote sensing data and to share those results across the remote sensing community. More information about JACIE is available at https://www.usgs.gov/ core-science-systems/eros/calval/jacie?qt-science_support_ page_related_con=3\#qt-science_support_page_related_con.

\section{Purpose and Scope}

The purpose of this report is to describe the specific sensor or sensing system, test its performance in three categories, complete related data analyses to quantify these performances, and report the results in a standardized document. In this chapter, the Gaofen-1 sensor is described. The performance of the system is limited to geometric, radiometric, and spatial. The scope of the geometric assessment is limited to testing 
the interior alignments of spectral bands against each other, and the exterior alignment is tested in reference to Landsat 8 Operational Land Imager (OLI).

The U.S. Geological Survey (USGS) Earth Resources Observation and Science Cal/Val Center of Excellence (ECCOE) project, and the associated system characterization process used for this assessment, follows the USGS Fundamental Science Practices, which include maintaining data, information, and documentation needed to reproduce and validate the scientific analysis documented in this report. Additional information and guidance about Fundamental Science Practices and related resource information of interest to the public are available at https://www.usgs.gov/about/organization/science-support/office-science-quality-and-integrity/fundamental-science-practices. For additional information related to the report, please contact ECCOE at eccoe@usgs.gov.

\section{System Description}

This section describes the satellite and operational details and provides information about the Gaofen-1 sensor.

\section{Satellite and Operational Details}

Key satellite and operational details of Gaofen-1 are listed in table 1.

\section{Sensor(s) Information}

The imaging sensor details for Gaofen-1 are listed in table 2. The relative spectral responses for Gaofen-1 are shown in figure 1.

Table 1. Satellite and operational details for Gaofen-1.

[kg, kilogram; NIR, near infrared; >, greater than; km, kilometer; ${ }^{\circ}$, degree; \pm , plus or minus; $\mathrm{m}$, meter]

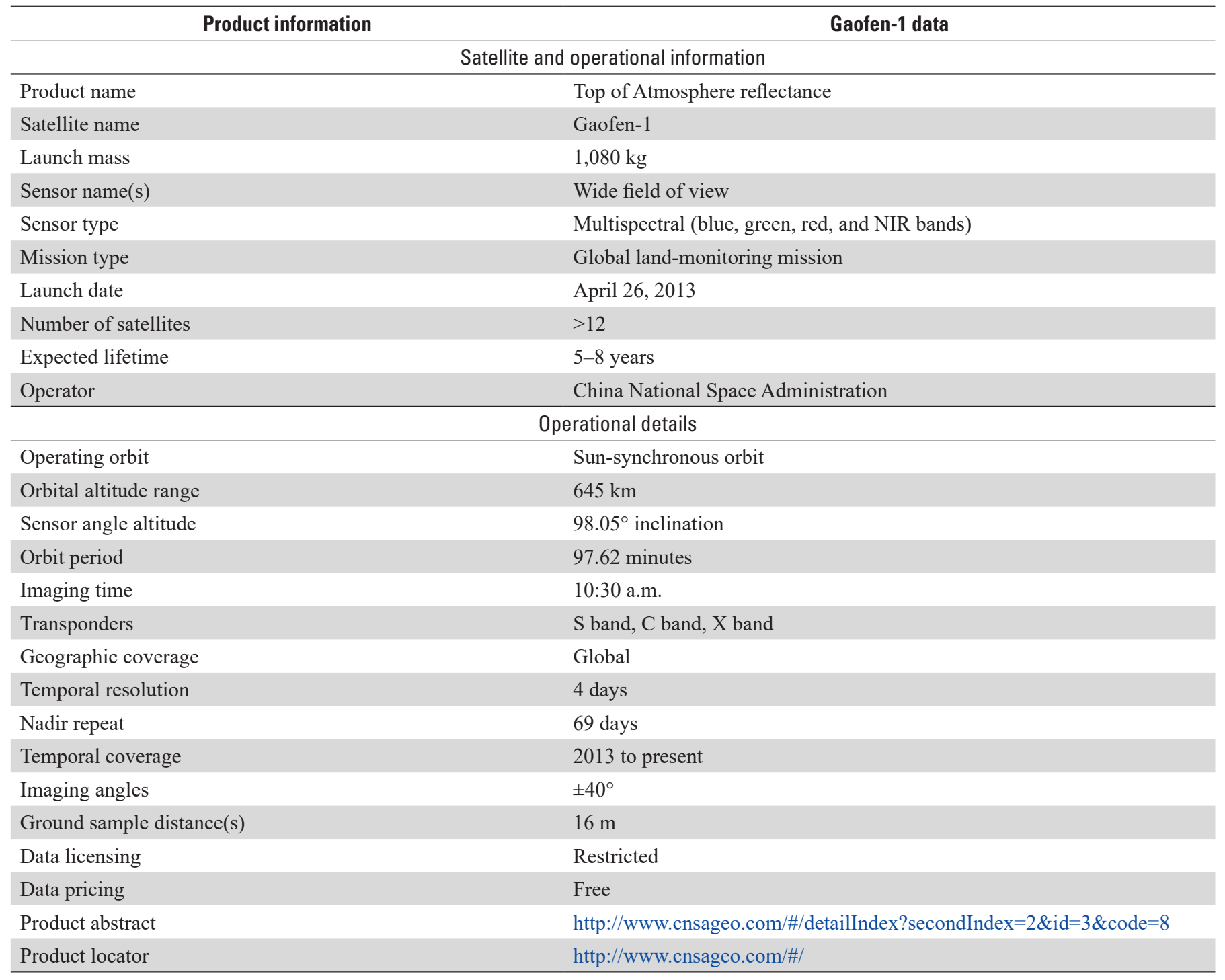


Table 2. Imaging sensor details for Gaofen-1.

[The wide field of view (WFV) sensor has a swath width of 800 kilometers (using four cameras-WFV1, WFV2, WFV3, and WFV4); $\mu$ m, micrometer; m, meter; NIR, near infrared]

\begin{tabular}{lcccc}
\hline \multirow{2}{*}{ Spectral band(s) details } & \multicolumn{3}{c}{ Gaofen-1 } \\
\cline { 2 - 5 } & $\begin{array}{c}\text { Lower band } \\
(\boldsymbol{\mu} \mathbf{m})\end{array}$ & $\begin{array}{c}\text { Upper band } \\
(\boldsymbol{\mu m})\end{array}$ & $\begin{array}{c}\text { Radiometric resolution } \\
(\mathbf{b i t s})\end{array}$ & $\begin{array}{c}\text { Ground sample distance } \\
(\mathbf{m})\end{array}$ \\
\hline Band 1-Blue & 0.45 & 0.52 & 10 & 16 \\
Band 2-Green & 0.52 & 0.59 & 10 & 16 \\
Band 3-Red & 0.63 & 0.69 & 10 & 16 \\
Band 4-NIR & 0.77 & 0.89 & 10 & 16 \\
\hline
\end{tabular}

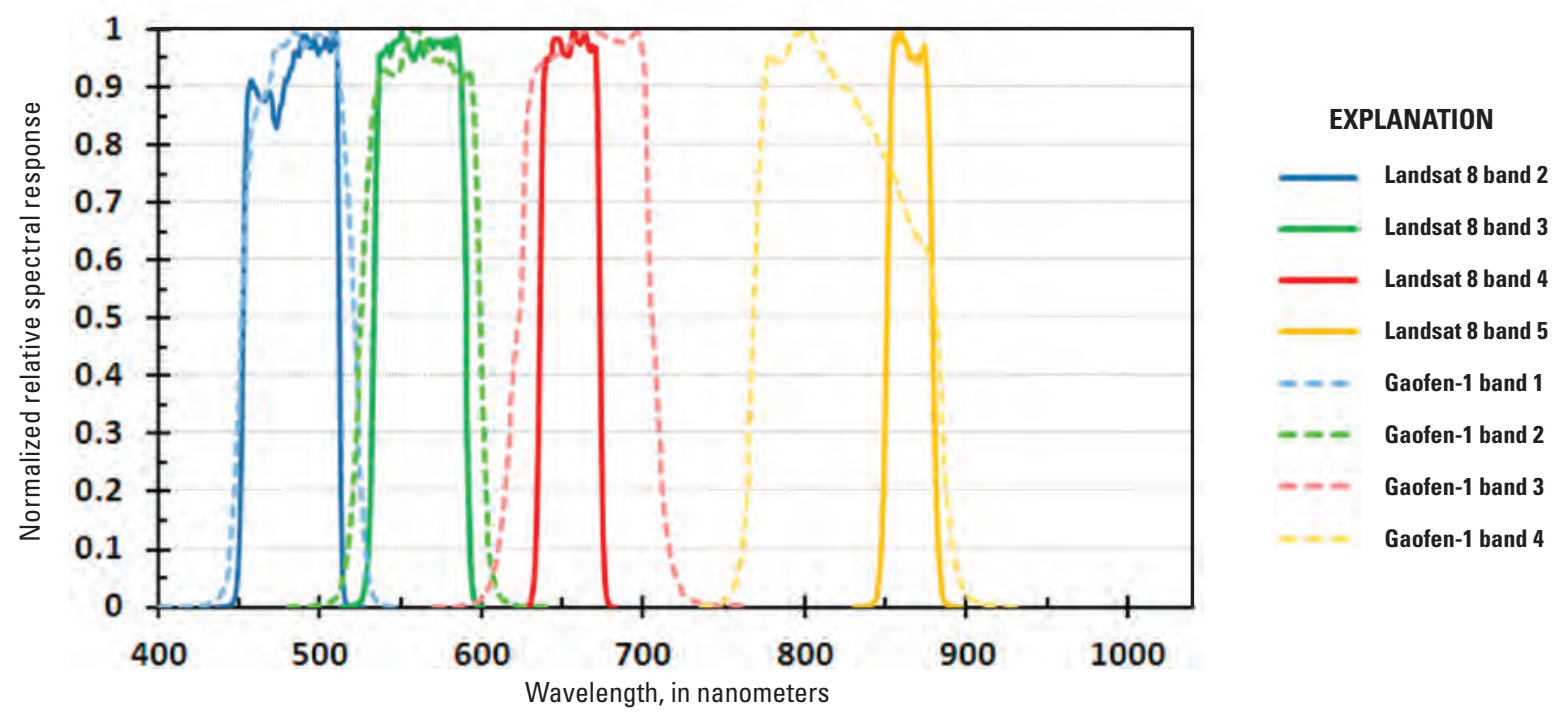

Figure 1. Gaofen-1 relative spectral response (modified from Li and others, 2016).

\section{Procedures}

The USGS ECCOE has established standard processes to identify Earth observing systems of interest and to assess the geometric, radiometric, and spatial qualities of data products from these systems.

The assessment steps are as follows:

- system identification and investigation to learn the general specifications of the satellite and its sensor(s);

- data receipt and initial inspection to understand the characteristics and any overt flaws in the data product so that it may be further analyzed;

- geometry characterization, including interior geometric orientation measuring the relative alignment of spectral bands and external geometric orientation measuring how well the georeferenced pixels within the image are aligned to a known reference;
- radiometry characterization, including assessing how well the data product correlates with a known reference and, when possible, assessing the signal-to-noise ratio; and

- spatial characterization, assessing the two-dimensional fidelity of the image pixels to their projected ground sample distance (GSD).

Data analysis and test results are maintained at the USGS Earth Resources Observation and Science Center by the ECCOE project.

\section{Measurements}

The observed USGS measurements are listed in table 3. Physical error, in meters, is calculated by the GSD (16 meters [m]) multiplied by the pixel error. Details about the methodologies used are outlined in the "Analysis" section. 
Table 3. U.S. Geological Survey measurement results.

[USGS, U.S. Geological Survey; m, meter; RMSE, root mean square error; L8 OLI, Landsat 8 Operational Land Imager; WFV, wide field of view sensor; \%, percent; FWHM, full width at half maximum; MTF, modulation transfer function; CNSA, China National Space Administration]

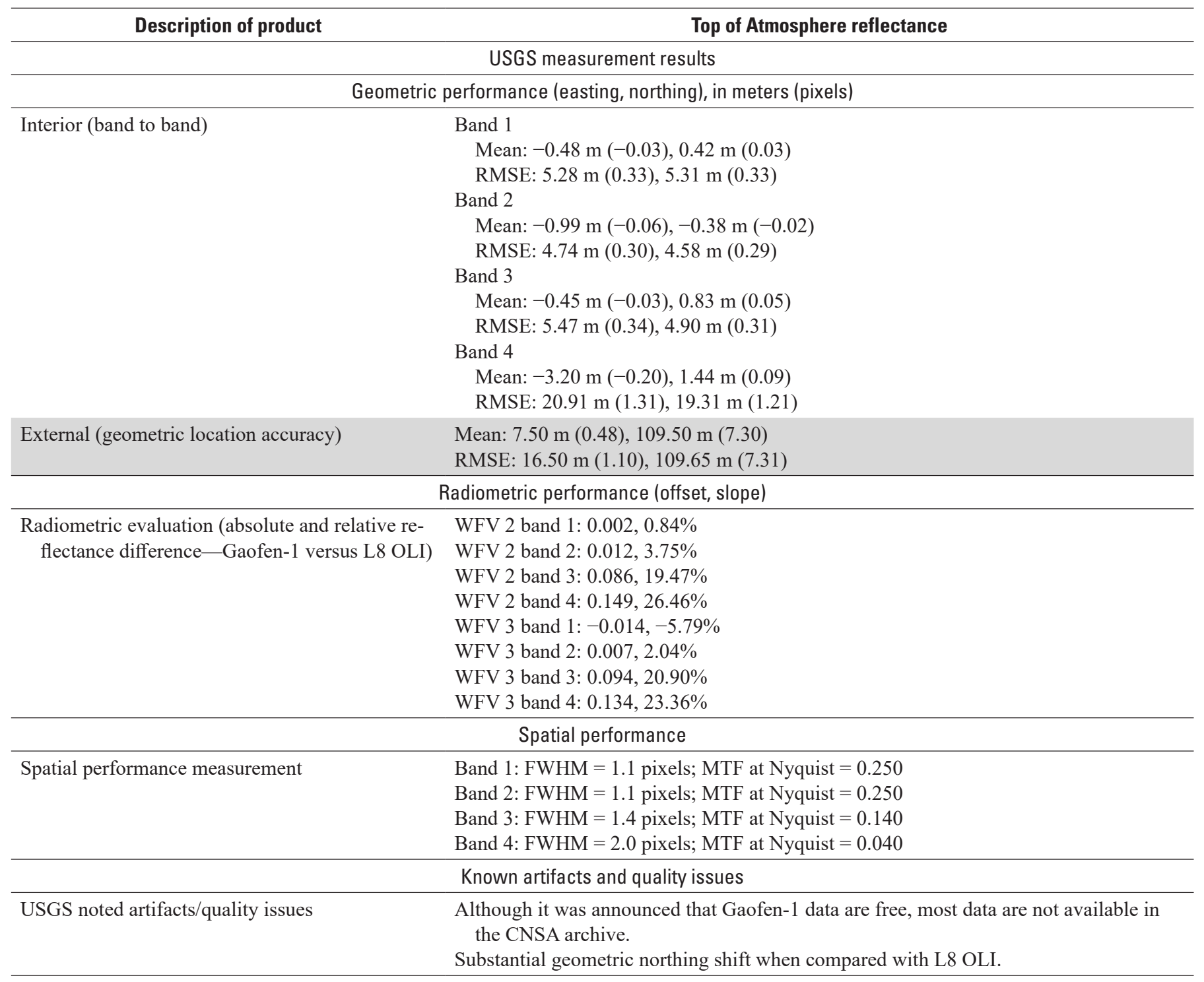

\section{Analysis}

This section of the report describes the geometric, radiometric, and spatial performance of Gaofen-1. Gaofen-1 geometric performance was analyzed using one scene whereas radiometric performance was analyzed using two near-coincident scene with Landsat 8 OLI.

\section{Geometric Performance}

The geometric performance for Gaofen-1 is characterized in terms of the interior (band-to-band alignment) and exterior (geometric location accuracy) geometric analysis results. Band to band (interior) analysis was performed by choosing one
Gaofen-1 band as a reference and analyzed alignment of other bands with respect to the reference band. Geometric location accuracy (exterior) geometric performance was performed by comparing Gaofen- 1 band with corresponding Landsat 8 OLI band.

\section{Interior (Band to Band)}

For this analysis, each band of the Gaofen-1 image was registered against all other bands using the Landsat Image Assessment System software to obtain the results. Results from one image (scene identifier: GF1_WFV2_W96.5 N42.6_20180809_L1A0003380205) were gathered to determine the mean error and root mean square error as listed in 
table 4 with results represented in pixels at a 16-m GSD. Greater misalignment was seen with band 4 (near infrared) of poor spatial quality and its spectral distinctness from bands $1-3$. Together, the interior and exterior geometric analysis results, as reported in the "Interior (Band to Band)" and "Exterior (Geometric Location Accuracy)" sections, provide a comprehensive assessment of geometric accuracy.

\section{Exterior (Geometric Location Accuracy)}

For this analysis, band 3 (red) of Gaofen-1 was compared against the Landsat 8 OLI panchromatic band, with a control uncertainty of $8 \mathrm{~m}$, because both have about $15-\mathrm{m}$ GSD. Additionally, an orthographic image (scene identifier: L1C_T14TPP_A016440_20200429T171636) obtained from aerial photogrammetric means over Sioux Falls, South Dakota, was used to visually verify the results. The Landsat Image Assessment System software was used to complete a mutual information-based correlation assessment, and the mean error and root mean square error results are listed in table 5 with results represented in pixels at a 16-m GSD. A geometric error vector map showing the direction of the shift and relative magnitude of the shift, when compared with the Landsat 8 OLI, is provided in figure 2 . Results after removal of the geometric bias (easting, 0.35 pixel; northing, 7.21 pixels) are shown in figure 3.

\section{Radiometric Performance}

For this analysis, cloud-free regions of interest were selected from near-coincident scene pairs to determine absolute and relative reflectance differences. Close nadir instruments were cross compared with the Landsat 8 OLI using a near-coincident scene from two Pseudo Invariant Calibration Sites: Egypt 1 (27.41 North, 26.38 East) and Libya 4 (28.55 North, 23.39 East). Pseudo Invariant Calibration Sites are the locations on Earth's surface that are stable over time. Because Egypt 1 and Libya 4 have similar radiometric intensity, and because of the lack of near-coincident scene options, the linear regression offset and slope were not calculated during this analysis. Statistical representations of the differences between the sensor pair are provided in tables 6 and 7 , and graphical representations of the differences are shown in figures 4-7.

Table 4. Band-to-band registration error (in pixels).

[RMSE, root mean square error]

\begin{tabular}{lcccc}
\hline Band & $\begin{array}{c}\text { Mean error } \\
\text { (easting) }\end{array}$ & $\begin{array}{c}\text { Mean error } \\
\text { (northing) }\end{array}$ & $\begin{array}{c}\text { RMSE } \\
\text { (easting) }\end{array}$ & $\begin{array}{c}\text { RMSE } \\
\text { (northing) }\end{array}$ \\
\hline Band 2 & & Reference-Band 1 & & \\
\hline Band 3 & 0.00 & -0.02 & 0.08 & 0.09 \\
Band 4 & 0.00 & -0.03 & 0.08 & 0.09 \\
\hline & -0.15 & 0.13 & 1.33 & 1.30 \\
\hline Band 1 & Reference-Band 2 & & 0.09 \\
Band 3 & 0.00 & 0.02 & 0.08 & 0.07 \\
Band 4 & 0.00 & -0.01 & 0.07 & 1.11 \\
\hline Band 1 & -0.31 & -0.12 & 1.18 & 0.09 \\
Band 2 & & Reference-Band 3 & & 0.07 \\
Band 4 & 0.00 & 0.03 & 0.08 & 1.21 \\
\hline
\end{tabular}

Table 5. Geometric error relative to Landsat 8 Operational Land Imager.

[ID, identifier; RMSE, root mean square error; $m$, meter]

\begin{tabular}{|c|c|c|c|c|}
\hline Scene ID & $\begin{array}{l}\text { Mean error } \\
\text { (easting) }\end{array}$ & $\begin{array}{l}\text { Mean error } \\
\text { (northing) }\end{array}$ & $\begin{array}{c}\text { RMSE } \\
\text { (easting) }\end{array}$ & $\begin{array}{c}\text { RMSE } \\
\text { (northing) }\end{array}$ \\
\hline $\begin{array}{l}\text { GF1_WFV2_W96.5_N42.6_20180809 } \\
\text { LL1A0003380205 }\end{array}$ & $\begin{array}{l}0.47 \text { pixel } \\
(7.50 \mathrm{~m})\end{array}$ & $\begin{array}{l}6.84 \text { pixels } \\
(109.50 \mathrm{~m})\end{array}$ & $\begin{array}{l}1.03 \text { pixels } \\
(16.50 \mathrm{~m})\end{array}$ & $\begin{array}{l}6.85 \text { pixels } \\
(109.65 \mathrm{~m})\end{array}$ \\
\hline
\end{tabular}




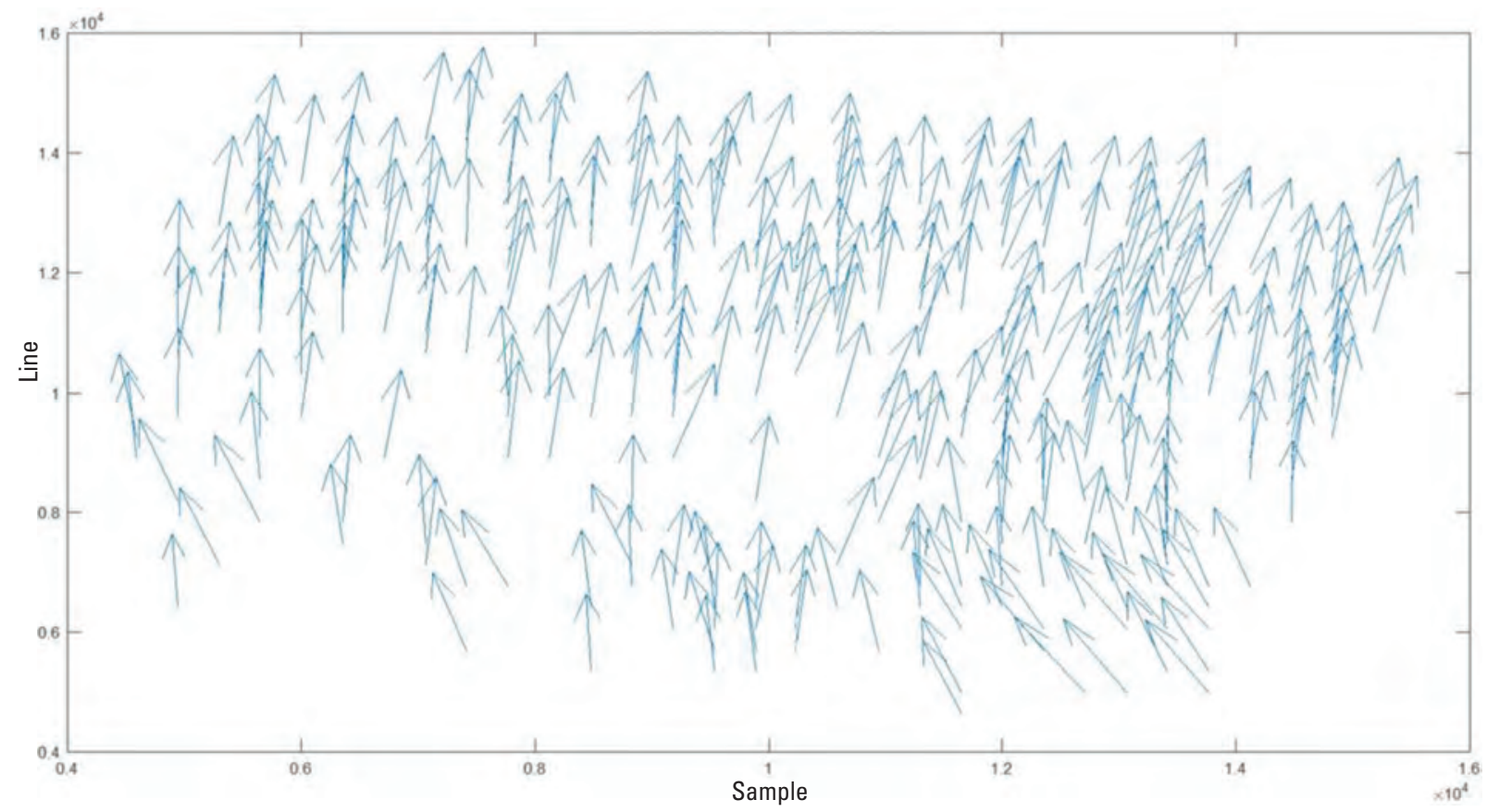

Figure 2. Relative geometric error comparison for Landsat 80 Operational Land Imager and Gaofen-1. 


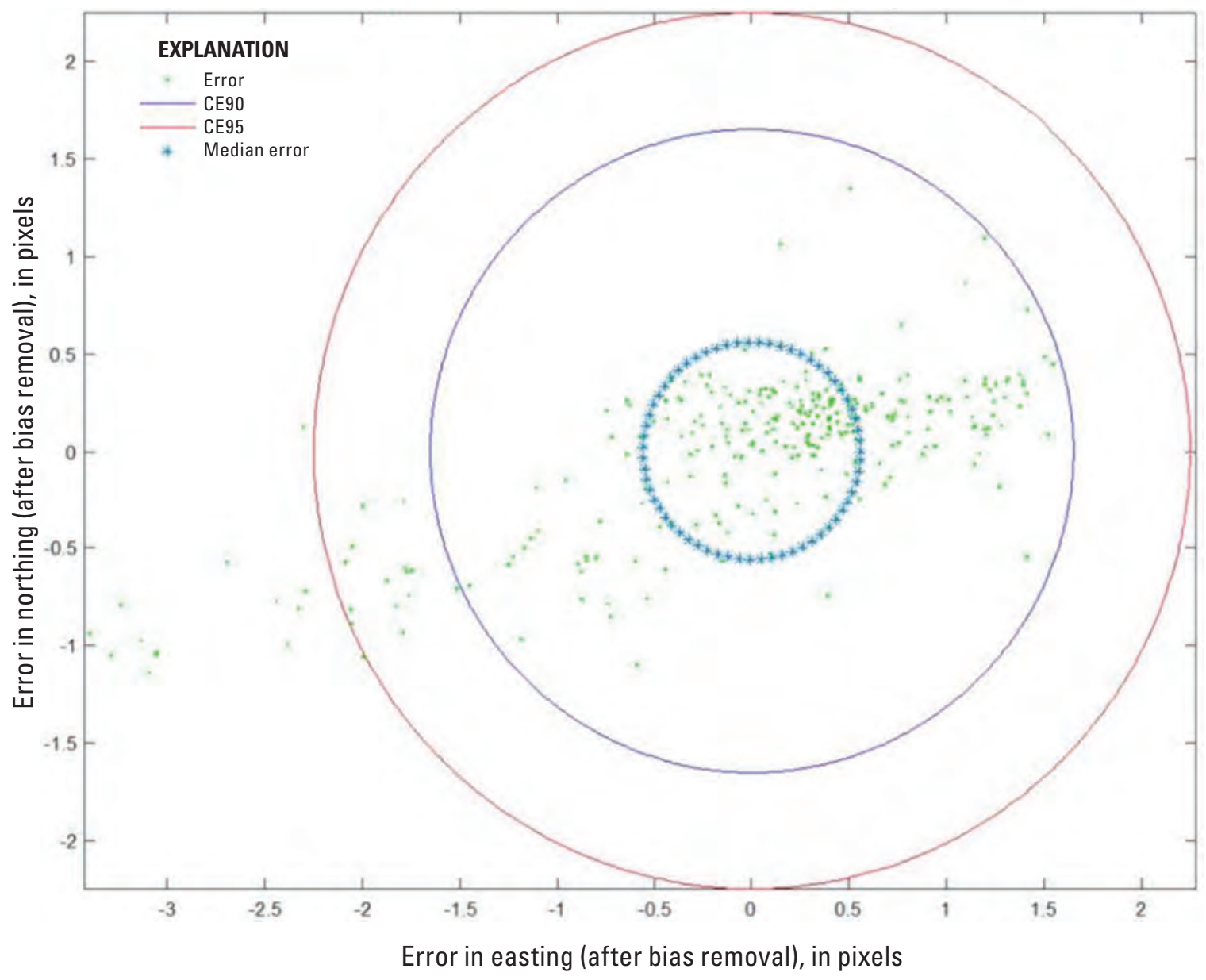

Figure 3. Relative geometric error comparison for Landsat 8 Operational Land Imager and Gaofen-1 after bias removal. CE90 and CE95 represent the radius of the circle such that there is a 90-percent and a 95-percent probability that the error lies within the circle, respectively.

Table 6. Top of Atmosphere reflectance comparison between Gaofen-1 wide field of view camera 2 and Landsat 8 Operational Land Imager over Egypt 1.

[NIR, near infrared; L8, Landsat 8; GF1, Gaofen-1; \%, percent]

\begin{tabular}{lcccc}
\hline \multicolumn{1}{c}{ Reflectance difference } & Band 1-Blue & Band 2-Green & Band 3-Red & Band 4-NIR \\
\hline Absolute difference (L8-GF1) & 0.002 & 0.012 & 0.086 & 0.149 \\
Relative difference (\%) & 0.84 & 3.76 & 19.48 & 26.46 \\
\hline
\end{tabular}

\section{Spatial Performance}

For this analysis, the image quality estimation software, designed based on Helder and others (2003), was used to determine the full width at half maximum and modulation transfer function at Nyquist frequency, as listed in table 8. 
Table 7. Top of Atmosphere reflectance comparison between Gaofen-1 wide field of view camera 3 and Landsat 8 Operational Land Imager over Libya 4.

[NIR, near infrared; L8, Landsat 8; GF1, Gaofen-1; \%, percent]

\begin{tabular}{lcccc}
\hline \multicolumn{1}{c}{ Reflectance difference } & Band 1-Blue & Band 2-Green & Band 3-Red & Band 4-NIR \\
\hline Absolute difference (L8-GF1) & -0.014 & 0.007 & 0.094 & 0.134 \\
Relative difference (\%) & -5.78 & 2.05 & 20.90 & 23.36 \\
\hline
\end{tabular}

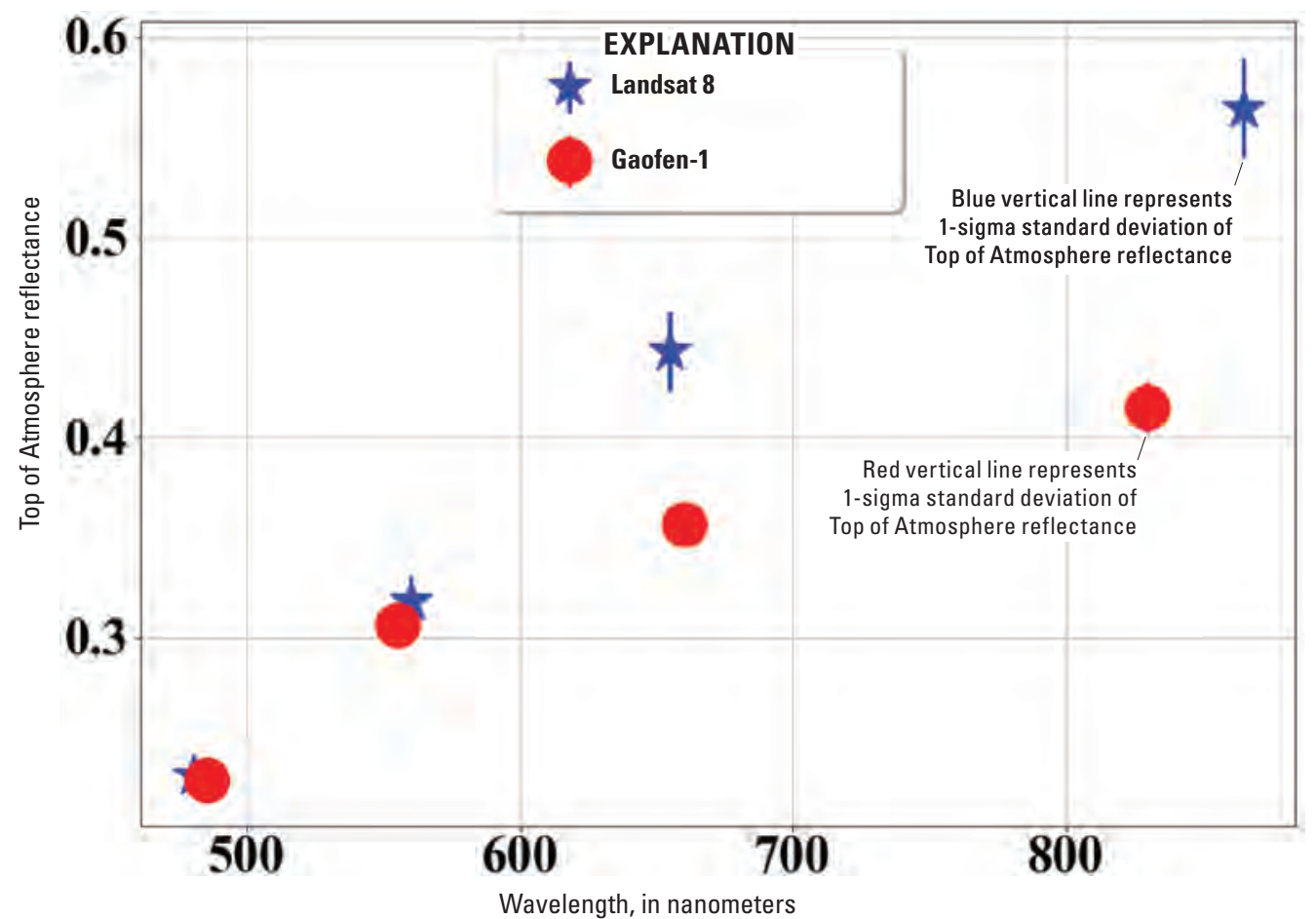

Figure 4. Top of Atmosphere reflectance comparison between Gaofen-1 wide field of view camera 2 and Landsat 8 Operational Land Imager over Egypt 1. 

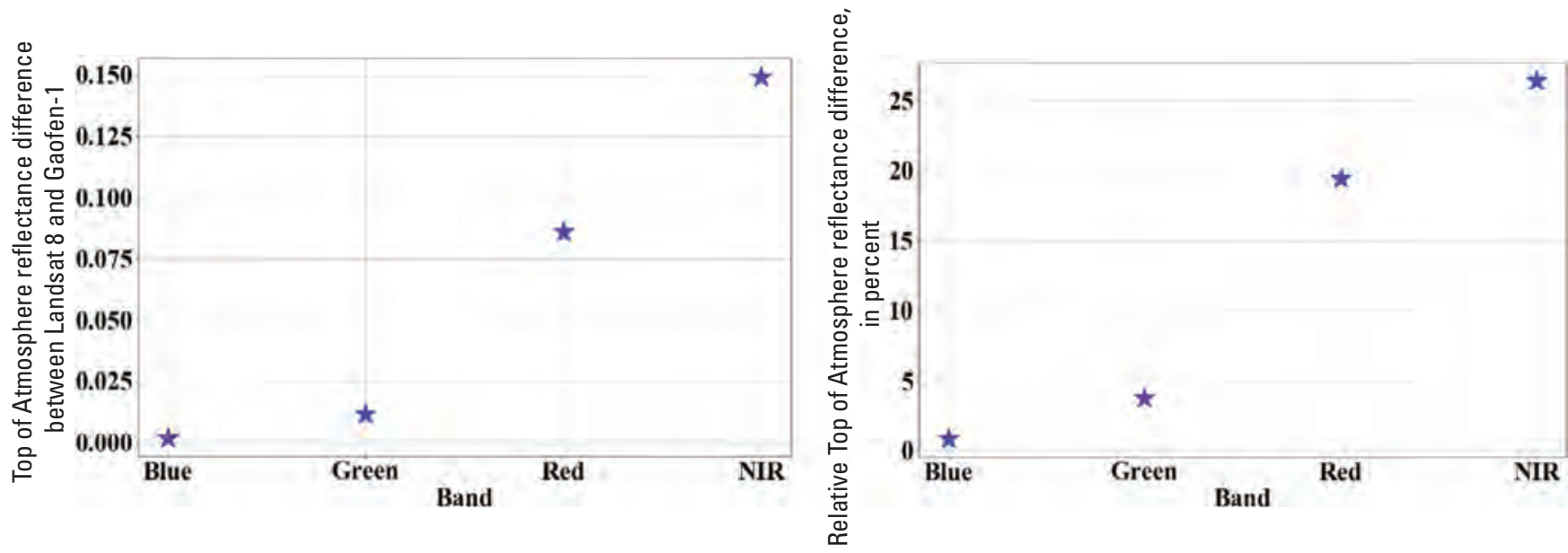

Figure 5. Top of Atmosphere reflectance difference between Gaofen-1 wide field of view camera 2 and Landsat 8 Operational Land Imager over Egypt 1. [NIR, near infrared]

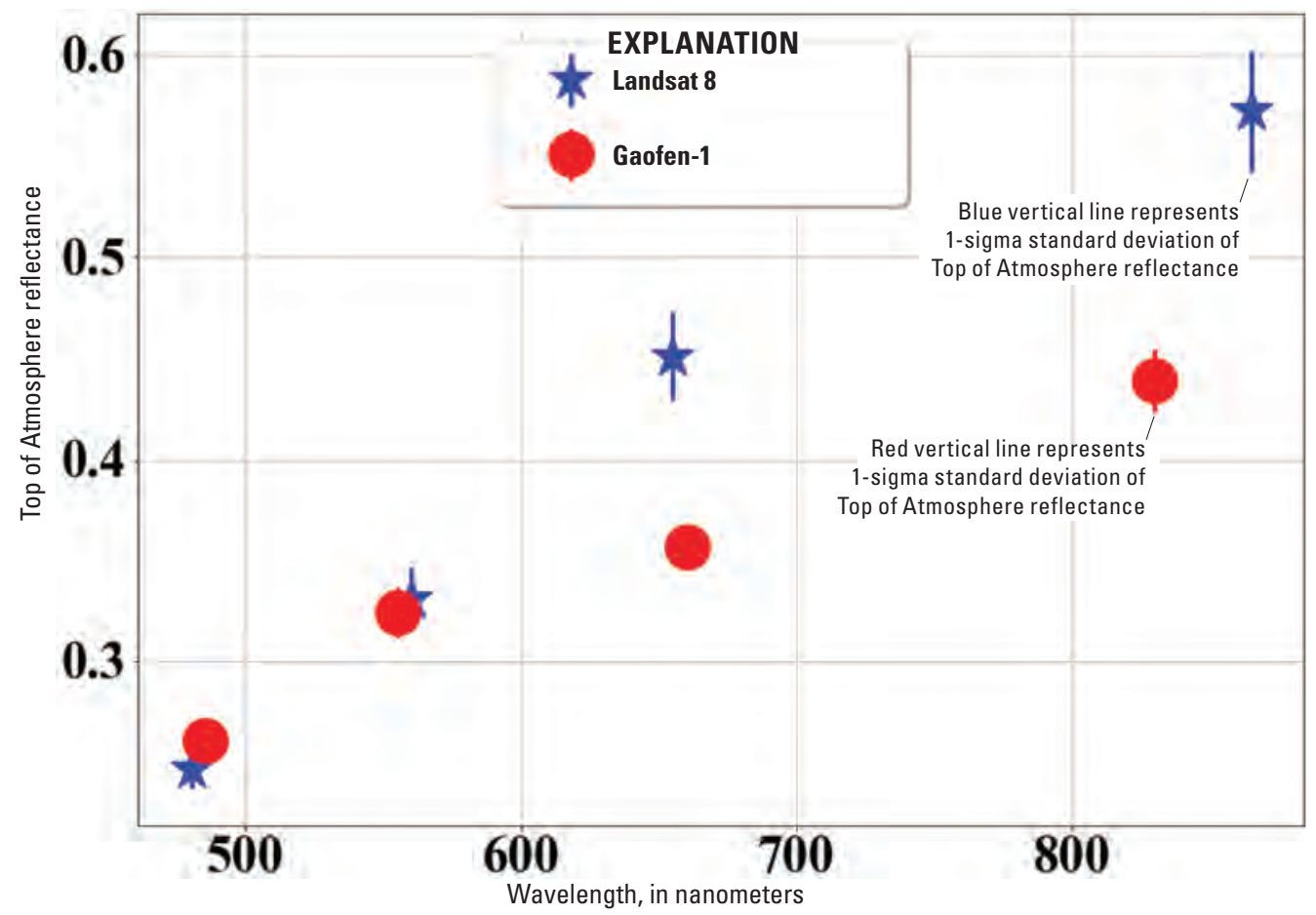

Figure 6. Top of Atmosphere reflectance comparison between Gaofen-1 wide field of view camera 3 and Landsat 8 Operational Land Imager over Libya 4. 

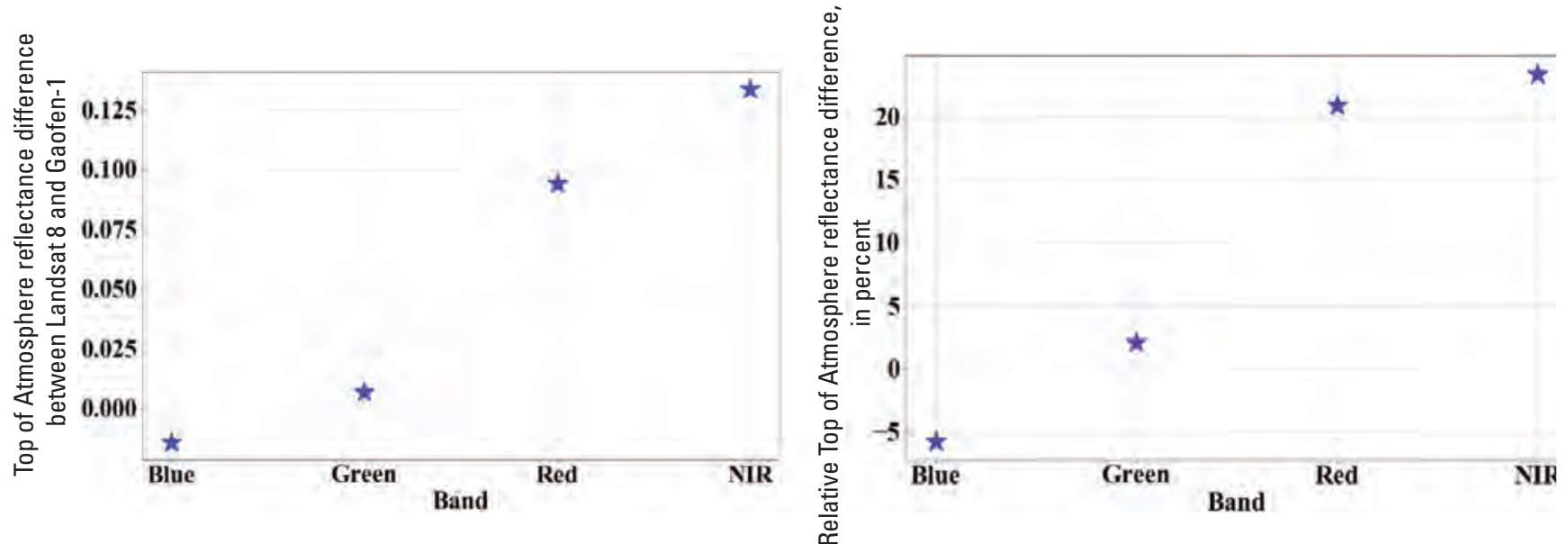

Figure 7. Top of Atmosphere reflectance difference between Gaofen-1 wide field of view camera 3 and Landsat 8 Operational Land Imager over Libya 4. [NIR, near infrared]

Table 8. Spatial performance of Gaofen-1.

[FWHM, full width at half maximum; MTF, modulation transfer function; NIR, near infrared]

\begin{tabular}{lcc}
\hline \multicolumn{1}{c}{ Spatial analysis } & FWHM & MTF at Nyquist \\
\hline Band 1-Blue & 1.1 pixels & 0.250 \\
Band 2-Green & 1.1 pixels & 0.250 \\
Band 3-Red & 1.4 pixels & 0.140 \\
Band 4 -NIR & 2.0 pixels & 0.040 \\
\hline
\end{tabular}

\section{Summary and Conclusions}

This report summarizes the sensor performance of the Gaofen-1 system based on the U.S. Geological Survey Earth Resources Observation and Science Cal/Val Center of Excellence (ECCOE) system characterization process. In summary, we have determined that this sensor provides an interior geometric performance of -0.48 meter $(\mathrm{m})(-0.03$ pixel) northing and $0.42 \mathrm{~m}(0.03$ pixel) easting offset for band 1 , $-0.99 \mathrm{~m}$ ( -0.06 pixel $)$ northing and $-0.38 \mathrm{~m}$ ( -0.02 pixels) easting offset for band $2,-0.45 \mathrm{~m}(-0.03$ pixel) northing and $0.83 \mathrm{~m}(0.05$ pixel $)$ easting offset for band $3,-3.20 \mathrm{~m}$ $(-0.20$ pixel $)$ northing and $1.44 \mathrm{~m}(0.09$ pixel $)$ easting offset for band 4 in band-to-band registration; similarly it has an exterior geometric performance of $7.50 \mathrm{~m}$ ( 0.48 pixel) easting and $109.50 \mathrm{~m}$ (7.30 pixels) northing offset, a radiometric performance of -0.014 to 0.149 (absolute reflectance difference), and a spatial performance of 1.1 to 2.0 pixels at full width at half maximum, with a modulation transfer function at a Nyquist frequency of 0.040 to 0.250 .
In conclusion, we have completed an ECCOE standardized system characterization of the Gaofen-1 sensing system. Although we follow characterization procedures that are standardized across the many sensors and sensing systems under evaluation, these procedures are customized to fit the individual sensor as we have done with Gaofen-1. Our team has acquired the data, defined proper testing methodologies, carried out comparative tests against specific references, recorded measurements, completed data analyses, and quantified sensor performance accordingly. The team also endeavored to retain all data, measurements, and methods. This is key to ensure that all data and measurements are archived accessible and that the performance results are reproducible.

The ECCOE project and associated Joint Agency Commercial Imagery Evaluation partners are always interested in reviewing sensor and remote sensing application assessments and would like to see and discuss information on similar data and product assessments and reviews. If you would like to discuss system characterization with the U.S. Geological Survey ECCOE and (or) the Joint Agency Commercial Imagery Evaluation team, please email us at eccoe@usgs.gov. 


\section{Selected References}

China National Space Administration, 2021, Standard of China space: China National Space Administration web page, accessed May 2020 at http://www.cnsa.gov.cn/ english/n6465684/n6465689/index.html?COLLCC= 4074507418\&.

Helder, D., Choi, T., and Rangaswamy, M., 2003, In-flight characterization of spatial quality using point spread functions: ISPRS International Workshop on Radiometric and Geometric Calibration, Gulfport, Miss., December 2-5, 38 -slide presentation.

Li, J., Feng, L., Pang, X., Gong, W., and Zhao, X., 2016, Radiometric cross calibration of Gaofen-1 WFV cameras using Landsat-8 OLI images-A simple image-based method: Remote Sensing, v. 8, no. 5, art. 411, 19 p. [Also available at https://doi.org/10.3390/rs8050411.]
Ramaseri Chandra, S.N., Christopherson, J.B., and Casey, K.A., 2020, 2020 Joint Agency Commercial Imagery Evaluation-Remote sensing satellite compendium: U.S. Geological Survey Circular 1468 (ver. 1.1, October 2020), 253 p. [Also available at https://doi.org/10.3133/cir1468.] [Supersedes USGS Circular 1455.]

U.S. Geological Survey, 2020a, EROS CalVal Center of Excellence (ECCOE): U.S. Geological Survey web page, accessed May 2020 at https://www.usgs.gov/core-sciencesystems/eros/calval/jacie?qt-science_support_page_related con=3\#qt-science_support_page_related_con.

U.S. Geological Survey, 2020b, Landsat missions - Glossary and acronyms: U.S. Geological Survey web page, accessed May 2020 at https://www.usgs.gov/core-science-systems/ nli/landsat/glossary-and-acronyms. 

For more information about this publication, contact:

Director, USGS Earth Resources Observation and Science Center 47914 252nd Street

Sioux Falls, SD 57198

605-594-6151

For additional information, visit: https://www.usgs.gov/centers/eros

Publishing support provided by the

Rolla Publishing Service Center 


\section{$\frac{1}{8}$}

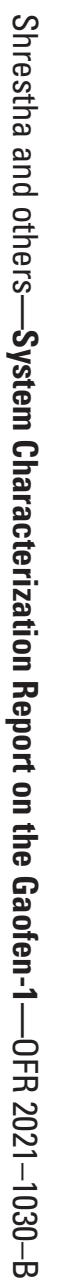

